\title{
INTERDISCIPLINARIDADE NO CONTEXTO ESCOLAR: ANÁLISE DO PROJETO PROFESSOR DIRETOR DE TURMA
}

\author{
Jean Mac Cole Tavares Santos \\ Brena Kesia Costa Pereira
}

Pesquisas realizadas sobre as políticas de interdisciplinaridade são inseridas em uma perspectiva que busca questionar as dualidades existentes entre proposta versus prática e política versus prática, produzindo as disputas de múltiplos sentidos no campo da educação. Neste artigo, lançamos mão das apropriações das chamadas teorias pós-críticas, que questionam uma transposição acrítica de epistemologias e concepções para a escola, focalizando a distinção entre disciplinas e os contornos que ela traz para a produção do conhecimento.

Para a análise, utilizamos o Projeto Professor Diretor de Turma (PPDT), que é um projeto originalmente português, traduzido no Brasil em meados de 2007, no estado do Ceará. Trazido por uma professora portuguesa com experiência em políticas públicas, esse foi, inicialmente, adotado por escolas de três cidades do Ceará como forma de teste e, logo depois, foi se expandindo pela maioria das escolas do estado.

Devido ao histórico de seu crescimento em território brasileiro e dos seus índices de aceitação das escolas, buscamos, neste artigo,explorar como o PPDT aborda a interdisciplinaridade no contexto escolar a partir dos seus documentos oficiais e da atuação do Professor Diretor de Turma (PDT) dentro da escola na execução do projeto.

Para isso, analisamos o folder de apresentação do PPDT, o Manual de Orientações das Ações do Professor Diretor de Turma e entrevistas semiestruturadas realizadas com quatro PDT de uma escola de ensino médio situada na cidade de Icapuí - $\mathrm{CE}^{1}$,que servirão de fontes para entender como a interdisciplinaridade é desenvolvida nos documentos e na prática. O artigo está dividido em três etapas, no qual constará uma abordagem sobre a interdisciplinaridade no contexto escolar, em seguida analisaremos a interdisciplinaridade no PPDT e, por fim, nossas considerações finais.

\footnotetext{
${ }^{1}$ Por motivos éticos, o nome da escola permanecerá no anonimato.
} 


\section{A INTERDISCIPLINARIDADE NO CONTEXTO ESCOLAR}

Para que se chegue ao conceito de interdisciplinaridade, torna-se necessário que se entenda o que é disciplinaridade ou que são as disciplinas. Começaremos então com a analogia das bibliotecas, que Alice Casimiro Lopes (2008) faz em seu texto "Por que somos tão disciplinares", para exemplificar esses primeiros conceitos. Nessa metáfora das bibliotecas, as disciplinas estariam disponíveis em estantes, classificadas de acordo com sua área e divididas em seções que as tornariam mais específicas. Dessa forma, esses conhecimentos seriam lidos, absorvidos separadamente e guardados/levados de volta à sua respectiva prateleira para que pudessem ser repassados da mesma forma para outras gerações e de pessoa para pessoa.

Alice afirma que a sociedade, em determinados momentos históricos, seleciona nessas bibliotecas conhecimentos que serão concebidos como mais importantes para a academia. Portanto, faz-se uma hierarquização do que já era organizado nessas estantes, garantindo uma ordem de aprendizado de que nascerão as disciplinarizações, pois “a intenção no campo de currículo não é reunir o universo de todos os livros possíveis, mas de exercer o poder da seleção do que se entende, pelo tempo ou pelo julgamento esclarecido, ou ainda por uma seleção dos dois como sendo o melhor” (LOPES, 2008, p. 202).

Vale ressaltar que essa ordem de aprendizado, selecionada pra entender e aprender determinada disciplina, depende da área de conhecimento em que está inserida. Essa ordem não é um processo estável e que serve como modelo para todas as disciplinas; nem muito menos é construída individualmente como se faz em uma biblioteca de uso pessoal, em que se vai comprando seus livros prediletos para formar o que a autora chama de "biblioteca dos sonhos".

Se a ordem de aprendizado dessas disciplinas é selecionada historicamente de tempos em tempos pela sociedade e/mas não é feita individualmente, então os documentos oficiais que versam sobre educação teriam sido criados com o intuito de selecionar os conteúdos que seriam supostamente mais pertinentes para que o aluno adquirisse os conhecimentos essenciais ou legítimos; o que segue a tradição de disciplinar em selecionar saberes que seriam melhores para todos ou para determinado grupo, portanto, segundo Alice, “algumas vozes são ouvidas, enquanto outras são silenciadas. Os sentidos, porém, são produtos tanto do que se ouve quanto do que é silenciado” (LOPES, 2004, p. 114).

Considerando as disciplinas a partir da analogia das bibliotecas, exposto acima, explanaremos na pergunta iniciada por Veiga-Neto (1996, p. 106) do que havia de errado em ser 
disciplinar, já que desde o início dos estudos educacionais os assuntos eram divididos em tópicos para que se pudesse fazer entender.

Segundo Veiga-Neto (1996, p. 109), a resposta para esse questionamento era, de fato, a separação e o isolamento de diferentes saberes entre si, o que fundamenta a separação de determinadas pessoas do resto do mundo.

Esse afastamento nos deixa sem compromisso com o destino de tudo o que nos cerca, incluindo aí até os outros homens e mulheres, de modo que ou não temos consciência dos males que um tipo de conhecimento fundado nessa separação pode causar à nossa volta, ou não vemos como problemáticas as relações que esse conhecimento estabelece com o mundo à nossa volta (VEIGA-NETO, 1996, p. 107).

A solução encontrada seria a desfragmentação, chamada de interdisciplinaridade. Uma espécie de aglutinação dos conhecimentos. Em um primeiro momento, a tentativa de interdisciplinarizar no sentido científico seria ver a diversidade em conjunto, procurando superar a dissociação, procurando “articular e produzir coerência entre os múltiplos fragmentos que estão postos [...]. Trata-se de um esforço no sentido de promover a elaboração de sínteses que desenvolvam a contínua recomposição da unidade entre as múltiplas representações da realidade” (LÜCK, 2013, p. 43).

No entanto, para Lopes (2008), não se pode negar que a disciplina existe, pois quando tomamos decisões sobre algo ou nos identificamos com um conceito nos juntamos a outras pessoas que têm demandas em comum na tentativa de hegemonizar uma teoria. Esse processo forma uma demanda social que inevitavelmente se divide, ou seja, se disciplinariza.

Segundo Lopes (2008, p. 207), o que estaria em foco não seria o sentido literal de disciplina como conjunto de saberes que são reproduzidos e categorizados, mas sim como construções sociais para atender a determinadas finalidades para a sociedade, que sustentam relações de poder.

Para reforçar seu argumento, a autora usa com o exemplo a contradição de quem sustenta que a disciplinarização não deve ser seguida, que são as divisões que se fizeram entre os termos: interdisciplinar, transdisciplinar e multidisciplinar. Essas nada mais são do que divisões disciplinares para construir um conceito que se reproduza com o intuito de hegemonização.Portanto, a disciplina existe, pois, quando tomamos decisões sobre algo ou nos identificamos com um conceito, nos juntamos a outras pessoas que têm demandas em comum na tentativa de hegemonizar uma teoria. 
As práticas dos sujeitos que compõem essas lutas se transformam no que Silva classifica de cultura, ou seja, uma tradição de como são interpretadas essas teorias. Nesse jogo de poder, “a cultura é um campo onde se define não apenas a forma que o mundo deve ter, mas também a forma como as pessoas e os grupos devem ser” (SILVA, 2005, p. 134). As tradições e as culturas de cada povo podem influenciar - ou até determinar - a interpretação e hegemonização de determinadas teorias.

Ao circularem no corpo social da educação, os textos, oficiais e não oficiais são fragmentados, alguns fragmentos são mais valorizados em detrimento de outros e são associados a outros fragmentos de textos capazes de ressignificá-los e refocalizá-los (LOPES, 2004, p. 113).

Assim, esses sujeitos sociais se agrupam ou se dividem a partir das suas interpretações sobre as demandas, formando suas próprias teorias.Vale ressaltar também que, se grupos diferentes se deparam com demandas em comum, eles se aliam até certo ponto na tentativa de homogeneização; logo após, se o objetivo for atingido e esses grupos não tiverem mais demandas em comum, a aliança é desfeita.Esses movimentos são chamados por Lopes de hibridismos.

Hibridismo, para Lopes (2004), trata-se de um processo de produção de conceitos e saberes a partir de visões de mundos, de cultura e de diferentes significados em que são associados a mecanismos simbólicos de legitimação de discursos, constituindo assim uma ressignificação ou novas ressignificações.

[...] as políticas curriculares são processos de negociação complexos, nos quais “momentos” como a produção dos dispositivos legais, a produção dos documentos curriculares e o trabalho dos professores devem ser entendidos como associados. Os textos produzidos nesses "momentos”, sejam eles registrados na forma escrita ou não, não são fechados nem têm sentidos fixos e claros (LOPES, 2004, p. 112).

Costa; Pereira (2013) vê a percepção de Alice sobre a interdisciplinaridade como um significante flutuante em que está para preencher o significante vazio da educação por meio desses hibridismos. Esses autores entendem que o significante flutuante atende a demandas específicas em formações discursivas diversas para preencher provisoriamente um significante vazio. Por isso, é preciso que se faça uma análise das relações de poder visando entender o processo de disputa desses diferentes agentes, pois o conhecimento, segundo Silva (2005, p. 135) é um processo que criado e interpretado socialmente.

A interdisciplinaridade escolar deve ser pensada a partir da especificidade da instituição escolar, sem estabelecer uma relação de subordinação entre o campo educacional e o campo científico. É preciso também compreender as influências como 
campos discursivos em mútua interação e não como uma relação de mera subordinação. Essa hegemonia permite compreender as disputas discursivas por significados que diferentes agentes, em campos de conhecimento específicos, procuram atribuir à interdisciplinaridade (COSTA; PEREIRA, 2013, p. 302).

Assim, os contextos em que casa instituição escolar está inserida podem ser usados para compreender o processo de disputas das disciplinas por hegemonia e, consequentemente, os processos utilizados para aplicar a interdisciplinaridade e com quais disciplinas. Seguindo, portanto, a definição da lógica de Ball de que as ações estão implícitas e seguem uma coerência que, no final, determinam a qual postura se aderiu. Essas lógicas de ação escolar "são conformidades derivadas [...] da observação de práticas e decisões na escola em relação a diversos aspectos de suas funções” (BALL; MAROY, 2009, p. 99), no qual essas escolas se diferenciam uma das outras por características específicas como a competitividade no mercado e os contextos que a regulam.

Portanto, a política pública não poderia ser somente implementada para a resolução de um problema, se levarmos em consideração os diversos fatores que constituem a escola, ou seja, o contexto escolar. Ball; Maguire; Braun (2006, p. 13) afirmam que, geralmente, esses problemas tentam ser resolvidos por meio dos documentos oficiais desses projetos para atender a uma demanda de nível nacional ou estadual. Assim, todos os outros processos que ocorrem dentro ou em torno de cada escola individualmente não são levados em consideração, essa vinculação de texto à prática e seus possíveis desdobramento são deixados de lado.

Para que esses outros processos educacionais pudessem ser mais bem explorados nos documentos oficiais e para efeito da pesquisa, o contexto de atuação de políticas foi dividido em quatro dimensões, definidas por Ball; Maguire; Braun (2016).A primeira dimensão, dos contextos situados, leva em consideração onde a instituição está situada, para que se reconheçam os tipos de alunos que a frequentam e o que eles esperam adquirir de conhecimento ao vir para a escola; A segunda dimensão, das culturas profissionais, se caracteriza pela análise do comprometimento, dos valores, das experiências e da forma de gestão dos professores atuantes nas escolas; Os contextos materiais referem-se ao que é físico na/dentro da escola, como a infraestrutura, os funcionários, os aparatados tecnológicos que a escola dispõe, seus orçamentos etc.; E os contextos externos são aspectos situados em fatores que rodeiam a escola, como a comunidade, relações com outras escolas, apoio de autoridades locais etc.

Essa interação das dimensões de contexto escolar com as culturas dos sujeitos que compõem a escola produzem as traduções das políticas públicas, pois os resultados das ações vão se constituir a partir dessas articulações, nos quais as individualidades e as identificações vão se hibridizando e 
se transformando em novos processos de representação. Então, para Ball; Maguire; Braun (2016), a elaboração de uma política pública deveria considerar o processo diverso que é sujeito a varias interpretações pelos atores que a encenam nas instituições educacionais.

\section{A INTERDISCIPLINARIDADE NO PROJETO PROFESSOR DIRETOR DE TURMA}

O PPDT teve sua primeira versão em Portugal em meados dos anos de 1960 no qual também recebeu nomenclaturas como Professor Diretor de Classe. Devido à boa recepção do projeto e seus bons índices em território europeu, em 2007, uma proposta de tradução dessa política pública foi apresentada no XVIII Encontro da Associação Nacional de Políticas e Administração da Educação (ANPAE) sobre as experiências das escolas portuguesas, que ocorreu no estado do Ceará. Segundo o folder de apresentação do projeto, em 2008, os municípios cearenses de Canindé, Eusébio e Madalena, foram os primeiros a aderirem à proposta de contextualização do projeto.

Tendo como base os quatro pilares da educação propostos por Delors ${ }^{2}$, o PPDT propõe a promoção do conhecimento individualizado de cada aluno pelos professores e grupo gestor das escolas participantes, visando combater a massificação de dificuldades e melhoria das relações entre professores, alunos e pais ou responsáveis.

A partir da adoção do PPDT na escola, estão disponíveis vagas para professores de qualquer área do ensino para serem os professores diretores de turma e se responsabilizarem pelos alunos de uma única turma. Ceará (2011) exige que, preferencialmente, esses professores devem ser essencialmente motivadores, ativos e terem espírito de liderança. Esse perfil vinculado aos pressupostos do projeto possibilitaria um

Conhecimento pormenorizado de cada um dos alunos, fornecendo os elementos de que precisa para melhor orientá-lo em suas necessidades específicas. Possibilita-lhe, também, atuar como mediador entre os alunos, os demais professores da turma e todos os envolvidos no processo educativo, no intuito de minimizar conflitos e imprevistos comuns à dinâmica escolar (CEARÁ, 2011, p. 02).

Esse conhecimento individualizado permite que o professor adentre e perceba o contexto em que o aluno está inserido não só na escola, mas também fora dela. Este objetivo do projeto está ligado diretamente a três dimensões de contexto trazidas por Ball Maguire; Braun (2016), a dos contextos situados, dos contextos externos e das culturas profissionais.

\footnotetext{
${ }^{2}$ Aprender a conhecer, aprender a fazer, aprender a viver juntos e aprender a ser.
} 
Assim, o Professor Diretor de Turma (PDT), a partir das suas atribuições, pode agir como uma espécie de mediador de conflitos, atuando nas resoluções de problemas do cotidiano escolar. Pois, tendo em vista a aproximação e o conhecimento maior da vida de cada um dos seus alunos, essa interação coopera para intervenções que poderiam ajudar os alunos a superarem suas dificuldades, tanto individuais como coletivas.

O PDT não recebe nenhuma gratificação por desempenhar esse papel. O que vai permitir o exercício desta função, segundo Ceará (2014), é a disponibilidade em quatro horas de sua carga horária semanal, onde uma hora é utilizada para as aulas de formação para a cidadania e as outras três horas são disponíveis para organização dos documentos instrumentais como o dossiê e portfólio solicitados pela SEDUC, atendimento a pais e/ou responsáveis e estudo orientado. O PDT fica encarregado de algumas atividades e essas responsabilidades devem ser somadas com o andamento e os planejamentos que o professor tem para ministrar sua disciplina curricular de lotação na escola.

Segundo Machado, “O Projeto Professor Diretor de Turma deve tornar-se parte constituinte do projeto político-pedagógico da escola, de forma que possa potencializar as ações educativas” (MACHADO, 2017, p. 31). Dentre as chamadas funções do PDT, há a tradução da política dentro da escola para viabilizar metas de médio e longo prazo. Esse fator também é uma forma de personalizar a política pública para o contexto em que a escola está situada e abrir possibilidades para que todos os PDT consigam traduzir a proposta desses documentos para sua sala de aula, especificamente. Essas metas buscam desenvolver, prioritariamente, três missões do projeto que são o estreitamento de laços entre a escola e a família dos alunos, conter a indisciplina dentro de sala de aula e auxiliar na aprendizagem significativa.

Devido ao papel mediador das atividades do projeto, a primeira pergunta da entrevista semiestruturada feita com PDT procurava saber o que eles, como profissionais da educação, entendem sobre interdisciplinaridade. As respostas obtidas apontaram para uma concepção mais condizente com a transversalidade que com os conceitos de interdisciplinaridade. Dentre as respostas, eles disseram que a interdisciplinaridade ocorre quando uma disciplina da grade curricular trabalha um tema universal que em nada está relacionado às outras disciplinas; em alguns casos, a interdisciplinaridade assumia uma postura em que uma disciplina da grade curricular se junta à outra e é trabalhado algo que elas têm em comum.

PDT 1: Interdisciplinaridade é o lugar onde você pode aceitar diversidade e vários temas podem ser propostos dentro da escola, pra gente discutir com nossos educandos a respeito de temas sugeridos que podem ser trabalhados dentro da sala de aula.

Entrevistador: Você pode dar exemplos dessas atividades? 
PDT 1: A questão da cidadania, do direito, a gente trabalha espaço de cada sociedade,a gente trabalha nossos projetos, também a questão da droga, violência na prostituição, a violência de menores e trabalho infantil porque nós temos alunos menores de idade.

PDT 2: A partir de o momento que a gente leva um texto pra ler, isso desenvolve a leitura oral, tem também a questão da interpretação, da compreensão que eles fazem dentro das informações, das pistas que os textos trazem. A gente pode envolver também [no texto] a questão da matemática, quando ele cita os índices, as porcentagens, debater como a pesquisa do texto chegou a esse índice número, fazer rapidinho de um cálculo pra mostrar. Entra também é questão de ciências humanas, quando o texto traz uma fala ou uma citação de um filósofo, a gente trabalha o ponto de vista, o conceito daquele filósofo.

Indagados sobre como eles compreendem a interdisciplinaridade no PPDT, as respostas apontaram para uma positividade em relação à abertura que o projeto dá para se trabalhar e relacionar tantos as disciplinas tradicionais como outros temas que seriam pertinentes para o crescimento pessoal do aluno.

PDT 4: A interdisciplinaridade no projeto está em todos os aspectos, então tudo cabe.

[...] Eu já cheguei a estudar sobre um assunto que não era da minha disciplina para ajudar um aluno. A interdisciplinaridade, ela está nisso aí, quando a gente sai do nosso ambiente.

Uma das atividades que o PPDT propõe aos PDT é a formação cidadã, chamada também de aulas de formação para a cidadania, que se constitui de ações para o engrandecimento pessoal e profissional do aluno por meio de trocas de experiências entre eles e os PDT. É reservada uma hora semanal para esses encontros, nessas aulas devem ser trabalhados temas relativos à cidadania, ao respeito às diferenças, às questões transversais e ao desenvolvimento da autoestima.

A atividade de formação para a cidadania "se configura como uma área curricular não disciplinar que deve ser trabalhada pelo viés da transversalidade” (CEARÁ, 2014, p. 13). Essa proposta de não disciplinarização da tarefa aponta para a interdisciplinaridade, que, nesse caso, é trazida pelos temas transversais.

Desse modo, apesar de nesse ponto o documento deixar claro a intenção de haver uma exploração de várias disciplinas, a expressão “área curricular não disciplinar” se contradiz, pois ela foi trazida de Portugal no processo de tradução do PPDT, no qual fazia parte de um movimento de reforma curricular desse país, integrando “o currículo obrigatório para todos os alunos. Mas não são 
‘disciplinas', no sentido que não fazem parte da definição prévia de um programa ou de um conjunto de temas, conhecimentos e métodos específicos, característico de uma disciplina ou de um grupo de disciplinas” (ABRANTES, 2002, p. 11). Tendo em vista os conceitos de disciplina e interdisciplinaridade definidos por Lopes, nesse caso, a formação cidadã pode sim ser considerada uma disciplina, já que ela divide a área em que está situada e o tipo de conhecimento que ela dissemina, mesmo que ela não esteja no hall de disciplinas mais tradicionais de currículo escolar.

Aos PDT, quando perguntados se a formação cidadã pode ou não ser uma ferramenta interdisciplinar, todos os participantes responderam que sim. Dessas respostas positivas, indagamos de que formas a interdisciplinaridade poderia acontecer em meio à prática da atividade de formação cidadã; os PDT consideraram que a interdisciplinaridade ocorria das várias discussões sobre temas diferentes que eram trazidos e debatidos nessas aulas.

Nessa perspectiva, a interdisciplinaridade, na visão dos PDT, não se correlaciona com as disciplinas da grade curricular tradicional. Perguntados sobre essa questão, eles disseram que a interdisciplinaridade também poderia ocorrer entre disciplinas como o português, por exemplo, e o tema escolhido pelos alunos para o debate de formação cidadã; na prática, segundo alguns professores, os textos trazidos para discussão melhoram a interpretação e o poder de argumentação dos alunos.

Ressalta-se aqui a consideração do PDT 2. Ela lembra que nem sempre esses debates acontecem de forma pacificada. Talvez pelos alunos não estarem acostumados a dialogar abertamente sobre temas tidos pela professora como polêmicos, houve casos o confronto de ideias foi tão forte que fez-se necessário solicitar ajuda da coordenação e/ou da diretoria da escola. O PDT 3 também relembra que teve aulas em que os alunos, ao falar sobre suas experiências com determinados temas, chegaram a chorar.

Percebemos também que os PDT não têm nenhum material que colabora com a execução dessas aulas. O projeto não disponibiliza textos, links ou outras ferramentas que tenham origem confiável para fundamentar as aulas. No caso da escola pesquisada, a coordenação é que busca alguns textos e vídeos sobre os temas mais pedidos pelos alunos para que o PDT utilize. Assim, além dos encaminhamentos das discussões serem totalmente diferentes de uma sala para outra, os textos e as métodos utilizados também não serão os mesmos.

Não há também, por parte do projeto, sugestões de possíveis temas para as aulas de formação cidadã. O termo “transversal” que é utilizado pelo PPDT, deixa aberto o que podem ser 
estudado, mas pode deixar de lado um tema que poderia gerar uma discussão interessante e que os alunos não lembraram na aula de escolha de tema.

Outra preocupação de um dos professores entrevistados é que os primeiros encontros da formação cidadã são utilizados para preenchimento de questões burocráticas do projeto. A burocracia aliada à falta de tempo disponível baixa a eficácia da execução do projeto.

PDT 4: Nós tínhamos cinco horas semanais, que já eram poucas. Aí eles acharam que era demais e não diminuíram os instrumentais, mas diminuíram uma hora, ficando só quatro. Aí, nem sempre essas aulas de formação para a cidadania é como a gente gostaria, porque a gente passa mais tempo na aula de formação fazendo coisas que a gente faria naquela hora que eles tiraram da gente. Por exemplo, eu tenho que levar os meninos para fazer a ficha autobiográfica com eles, eu tenho que pegar os meninos para tirar a foto e colocar no sistema, então, tudo isso, só dá para ser feito na hora disponível para formação cidadã. Então, às vezes a aula de formação cidadã não alcança nossas expectativas por conta da questão do tempo. A gente tem muita coisa para fazer e tem pouco tempo.

Outra atividade do PPDT é oestudo orientado. Esse compreende a formação de um grupo de estudos de uma hora semanal, mediado pelo PDT ou por alunos monitores, para repassar e refletir sobre atividades sobre conhecimentos pertinentes ao crescimento pessoal, profissional, social e acadêmico dos orientandos. Essas atividades contribuem, segundo Machado (2017), para proporcionar aos educandos a prática da investigação, nas resoluções de tarefas e na melhoria das relações interpessoais.

Segundo os PDT entrevistados, o estudo orientado, apesar de ser executado, não consegue atingir o seu potencial inteiramente. Os PDT consideram a falta de tempo como sendo o principal fator que impede a execução da atividade.

PDT 4: O projeto é bom. E ele funciona muito, sem funcionar como deveria, imagine aí se ele funcionasse como deveria! Deus me livre de um nome da escola sem um $\mathrm{DT}^{3}$.

Essa atividade do projeto é caracterizada também como “uma área curricular não disciplinar e transversal” (CEARÁ, 2014, p. 15). O documento vai sendo mais claro quanto ao seu posicionamento quando esclarece o objetivo dessa ação do projeto, no qual a interdisciplinaridade vai além de dialogar com as disciplinas, no PPDT, ela está em "fazer os alunos desenvolverem seus próprios métodos de estudo, sua capacidade de autorregulação, autoavaliação e heteroavaliação”

\footnotetext{
${ }^{3}$ DT é a abreviação de Diretor de Turma dada pelos professores da escola pesquisada, essa abreviação equivale a PDT.
} 
(CEARÁ, 2014, p. 15), aliando os contextos em um processo hibridizado para que algo em disputa se hegemonize e se adeque ao que era buscado até então.

Entretanto, não fica claro no documento o que seriam esses processos de autorregulação, autoavaliação e heteroavaliação, quais os parâmetros para estar regular e para avaliar, ou, ainda, de que formas esses alunos poderiam avaliar e serem avaliados. E mesmo se as definições desses significantes estivessem escritas, não haveria como garantir a uniformidade desses processos, devido a múltiplas interpretações de alunos de cada grupo e os diferentes contextos inseridos em cada escola.

Apesar disso, a escola em questão consegue contextualizar e reinterpretar os documentos oficiais do projeto, adequando-os a sua realidade. E isso foi possível de ser percebido quando perguntamos aos entrevistados como o PDT pode relacionar as atividades dos estudos orientados das disciplinas da grade curricular com o que o projeto propõe, ou seja, que os alunos desenvolvam métodos de estudos que se adequem ás suas necessidades específicas, se autorregulando, autoavaliando e praticando a heteroavaliação.

Desse último questionamento, constatamos que, os PDT da escola pesquisada não conseguem atender individualmente todos os alunos que necessitam de estudos orientados devido às salas superlotadas, que chegam a 45 alunos - como relata o PDT 4, no caso das primeiras séries da escola-, aliada a recorrente reclamação da falta de tempo. Para tornar o estudo orientado uma atividade viável para a escola, os professores criaram uma ferramenta que eles chamaram de “células de aprendizagem”.

PDT 3: A gente retirava da sala esses alunos, não que fossem os melhores alunos porque todos os alunos são bons, mas os que tinham mais habilidades com determinadas disciplinas. A gente fazia grupos, grupos de estudo. Aí, por exemplo, ia de acordo com a comunidade, porque nem sempre eles poderiam se encontrar na escola; quem morava mais perto de quem? Qual é o dia que vocês iam se encontrar? A gente faz essa avaliação.

Entrevistador: Você acha que, como PDT, conseguiria fazer o que o projeto propõe, que é o acompanhamento individualizado?

PDT 3: Não. De jeito nenhum. [...] A gente já até fez células de aprendizagem dentro da sala de aula, quando, depois das avaliações, os alunos que passavam tinham que 
continuar assistindo aula para que se fizesse a revisão do conteúdo para a paralela ${ }^{4}$. O nosso objetivo era quem passou ficar na sala para ajudar quem não passou.

PDT 4:Acontece também dos alunos que eu sei que tem facilidade com cálculos, aí eu posso orientar, pegar esses alunos que têm mais facilidade e que têm disponibilidade em ajudar e fazer uma célula de estudo lá na comunidade dele ou aqui na escola, aí eu tenho obrigação de fazer um comunicado dizendo para os pais que naquele dia, naquele horário, o aluno vai para escola para isso.

Segundo os PDT, a células de estudo estão dando certo até o momento, apesar de não ser o ideal para o projeto. Nelas os professores das disciplinas são convidados a ter um momento com esses alunos para esclarecer dúvidas e os alunos entre si compartilham seus conhecimento. Tudo isso ocorre sob a supervisão do PDT ou de um aluno monitor. E, para os alunos que necessitarem de um acompanhamento mais intenso, o PDT procura ajudá-lo individualmente.

Perguntados sobre a disponibilidade dos outros professores que não são PDT para ajudar, os entrevistados disseram que a maioria dos docentes que se comprometem a auxiliar são os professores readaptados.

PDT 4: Tem coisas que eu não tenho como ajudar, mas eu posso procurar uma maneira diferente de ajudar. Eu posso procurar um professor que se disponibilize a dar uma aula uma vez por semana, e eles dão. Tem muito professor readaptado de matemática lá na biblioteca que ajuda.

Ceará (2014) traz que

É importante a colaboração dos outros professores para este momento, uma vez que o Diretor de Turma tem formação em apenas uma disciplina. Cada professor sugere atividades que possam auxiliar os alunos com dificuldades de aprendizagem e devem orientar os alunos monitores de suas disciplinas a desenvolver atividades em colaboração com aqueles (CEARÁ, 2014, p. 15).

Assim, o processo interdisciplinar se dá, no PPDT, a partir de uma demanda em comum do objetivo do projeto, em querer ajudar os alunos a interagirem melhor com as disciplinas da grade curricular da escola; e do professor dessas disciplinas, em querer que os seus alunos treinem os conteúdos repassados em sala de aula para que aprendam. Assim, nesse processo de demandas em comum, o aluno entra como personagem principal e transforma/hibridiza esse conteúdo aprendendo de uma forma singular.

\footnotetext{
${ }^{4}$ Espécie de recuperação de notas para os alunos que não atingiram a média no período regular.
} 
O manual de orientações do PDT ressalta as preocupações do projeto em incluir os constituintes da comunidade escolar para o progresso do programa desde a sua “implantação”, exigindo, antes de as primeiras ações serem iniciadas, a “apropriação por toda comunidade escolar. Ter conhecimento do conceito e das atribuições de cada segmento, compreender o contexto escolar, bem como manter integradas as ações faz com que a implantação logre êxito e implemente-se na escola” (CEARÁ, 2014, p. 49). Assim, além do conhecimento do contexto da vida de todos os alunos da sua sala, para o projeto, é importante também que o PDT leve em consideração as outras dimensões de contexto na execução do PPDT.

A implementação de uma GSA ${ }^{5}$ depende, primordialmente, do trabalho conjunto de todos os segmentos da comunidade escolar - alunos, pais, núcleo gestor e professores. Ainda que todos os passos de implantação sejam seguidos, o compromisso e a interação entre os segmentos são os elementos que garantem que a execução do processo logrará êxito. Portanto, faz-se necessário propiciar uma rotina de acompanhamento e orientação, bem como assegurar as condições necessárias para o cumprimento efetivo das atividades (CEARÁ, 2014, p. 50).

Portanto, o documento ressalta que essa preocupação com o(s) contexto(s) em que o projeto está inserido deve ser contínua. Destacamos isso, pois, como dito por Lopes (2008), os processos estão em movimento constante, se ressignificando e gerando outros contextos.

\section{CONSIDERAÇÕES FINAIS}

Tratando-se de interdisciplinaridade e contexto escolar, podemos considerar que o PPDT se utiliza em seus documentos oficiais de recursos para promover uma integração entre a comunidade escolar, promovendo atividades que abrangem discussões e reflexões não só sobre as disciplinas que compõem a grade curricular da instituição, mas também os outros contextos que estão direta e indiretamente relacionados ao crescimento intelectual do alunado, partindo da construção do pensamento crítico e da possibilidade de gerar autonomia.

Apesar das atividades levarem a ações que promovem e realizam o processo de hibridização de demandas das disciplinas, o documento deixa explícito na sua escrita uma tentativa de interdisciplinaridade das atividades que devem ser realizadas na execução do projeto, utilizando palavras como implementação, implantação e a expressão “não disciplinar”.

\footnotetext{
${ }^{5}$ Modelo de Gestão em Sala de Aula.
} 
Com os relatos obtidos por meio das entrevistas semiestruturadas, podemos perceber que os PDT não conseguem seguir à risca o que os documentos pedem, devido a grande demanda de ações e do pouco tempo disponível, prejudicando assim questões que vão desde o planejamento da aula para formação cidadã que envolva mais ferramentas/sujeitos na prática interdisciplinar até o apoio individualizado ao aluno. Essas inadequações do projeto forçam os PDT a buscarem alternativas que supram e auxiliem na execução das atividades de uma maneira que ultrapassem essas barreiras contextuais.

Para que se possa fechar - por enquanto - a discussão posta neste artigo, consideramos que, nos dois documentos analisados, apesar da linguagem empregada seguir um padrão habitual de documentos sobre políticas públicas e currículo escolar, quando se examina de forma mais abrangente o que as ações desse projeto objetivam, é possível perceber que há um viés direcionado a interdisciplinaridade que leva em consideração algumas das dimensões de contexto, as demandas que cada disciplina traz consigo e o processo de tradução que cada escola faz quando põe em prática o PPDT. No entanto, quando se trata da execução do projeto na escola não se pode inferir que essas ações são postas em prática da mesma forma em todas as escolas. 


\section{REFERÊNCIAS}

ABRANTES et al. Reorganização Curricular do Ensino Básico: novas áreas disciplinares. Lisboa: Ministério da Educação, Departamento da Educação Básica, 2002.

BALL, Stephen J.; MAGUIRE, Meg; BRAUN, Annette. Como as escolas fazem as políticas: atuação em escolas secundárias. Trad.: Janete Bridon. Ponta Grossa: Editora UEPG, 2016. 220 p.

; MAROY, Christian.Lógicas de ação escolar como mediação e compromisso entre dinâmica interna e restrições e pressões externas.A Journal of Comparative and International Education, 2009, 99-112 p.

CEARÁ. Projeto Professor Diretor de Turma. Folder. Seduc/Anpae, 2011. Disponível em: <http://www.seduc. ce.gov.br/images/professor_diretor_turma/projeto_professor_diretor_de_turma.pdf>. Acesso em: 24 abr. 2017.

Secretaria da Educação. Manual de orientações das ações do professor diretor de turma/ Secretaria da Educação; Coordenadoria de Cooperação com os Municípios. Fortaleza: SEDUC, 2014.

COSTA, Hugo Heleno Camilo. PEREIRA, Talita Vidal. Sentidos e interdisciplinaridade articulados nas políticas de currículo: o caso das disciplinas Ciências Naturais e Geografia. Cadernos de Educação, | FaE/PPGE/UFPel, Pelotas, jan./abr. 2013.

LOPES, Alice Casimiro. Por que somos tão disciplinares? ETD - Educação Temática Digital, Campinas, v. 9, n. esp., 2012, out. 2008.

. Políticas curriculares: continuidade ou mudança de rumos? Revista Brasileira de Educação [on-line], n. 26, p. 109-118, maio/jun./jul./ago. 2004

LÜCK, Heloísa. Pedagogia Interdisciplinar: fundamentos teórico-metodológicos / Heloísa Lück. 18. ed. Petrópolis, RJ: Vozes, 2013.

MACHADO, Emanuel Kaúla Santos. Constituintes de uma práxis de mediação pedagógica do Professor Diretor de Turma. 127 f. Dissertação (Mestrado em Educação) - Centro de Educação, Universidade Estadual do Ceará, Fortaleza, 2017.

SILVA, Tomaz Tadeu da. Documentos de Identidade: uma introdução às teorias do currículo. Belo Horizonte: Autêntica, 2005.

VEIGA NETO, Alfredo. Currículo, disciplina e interdisciplinaridade. Revista Brasileira de Ciências do Esporte, v. 17, n. 2, 1996, p. 128-137. 


\section{RESUMO}

Este artigo busca analisar como o Projeto Professor Diretor de Turma aborda a interdisciplinaridade no contexto escolar a partir dos seus documentos oficiais e de entrevistas realizadas com Professores Diretores de Turma. O método utilizado é o da análise bibliográfica, documental e de entrevistas, no qual o folder de apresentação do referido projeto, o Manual de Orientações das Ações do Professor Diretor de Turma e a opinião dos professores participantes do projeto serão fontes para entender como a interdisciplinaridade é desenvolvida nesses documentos e suas relações com o(s) contexto(s) da instituição em que está inserida. $\mathrm{O}$ artigo está dividido em três etapas; na introdução constará uma abordagem sobre a interdisciplinaridade no contexto escolar, em seguida analisaremos a interdisciplinaridade no PPDT e, por fim, as conclusões do artigo. Como referencial teórico, utilizamos autores como Veiga-Neto (1996) para definir o que é interdisciplinaridade, os conceitos de Lopes; Macedo (2011) sobre interdisciplinaridade e hibridismo, Silva (2005) para as discussões sobre a interdisciplinaridade no currículo e Ball; Maguire; Braun (2016) para as definições sobre dimensões de contexto.

Palavras-chave: Projeto Professor Diretor de Turma. Interdisciplinaridade. Contexto.

\section{ABSTRACT}

This article aims to analyze how the Projeto Professor Diretor de Turma approaches the interdisciplinarity in the school context from his official documents and interviews with Professores Diretores de Turma. The method used is the bibliographic, documentar and interviews analysis, in which the presentation folder of the Project, the Manual of Orientations of the Actions of the Professor Diretor de Turma and the opinion of the teachers participating in the project will be sources to understand how the interdisciplinarity is developed in these documents and their relations with the context(s) of the institution in which the project is part. The article is divided into three stages; in the introduction will include an approach on interdisciplinarity in the school context, then we will analyze the interdisciplinarity in the PPDT, and, the conclusions of the article. As a theoretical reference, we use authors like Veiga-Neto (1996) to define what is interdisciplinary, the concepts of Lopes; Macedo (2011) about interdisciplinarity and hybridism, Silva (2005) for the discussions about interdisciplinarity in the curriculum and Ball; Maguire; Braun (2016) for definitions about context dimensions.

Keywords: Projeto Professor Diretor de Turma. Interdisciplinarity. Context. 